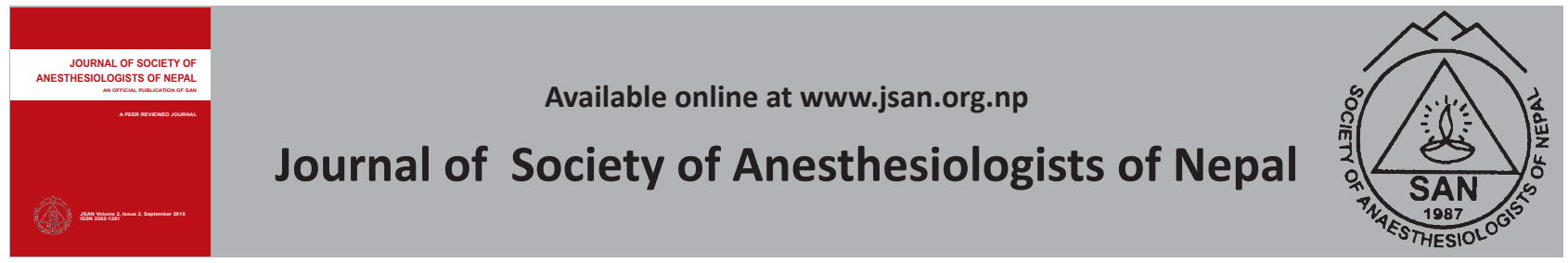

Case Report

\title{
Dexmedetomidine as an anaesthetic adjunct for management of difficult airway in a patient with facial injury following bear maul
}

Bashu Dev Parajuli, Rejin Kumar Udaya, Anubhav Sharma, Gentle Sunder Shrestha

Tribhuvan University Teaching Hospital, Maharajgunj, Kathmandu, Nepal

\author{
ARTICLE INFO \\ Article History \\ Received 08.04.2015 \\ Accepted 30.07.2015 \\ Published 10.09.2015 \\ (C) Authors retain copyright \\ and grant the journal right \\ of first publication with the \\ work simultaneously licensed \\ under a Creative Commons \\ Attribution License that allows \\ others to share the work with \\ an acknowledgement of the \\ workss authorship and initial \\ publication in this journal.
}

\begin{abstract}
Abstract : The management of difficult airway is one of the most challenging tasks for the anaesthesiologist. Life threatening cannot intubate and cannot ventilate situation can be avoided by performing awake-fibreoptic intubation. Although there are many techniques described for fibreoptic intubation but relative merits and demerits of each technique should be considered. The key to successful awakefibreoptic intubation depends upon the meticulous preparation of the patient and the equipments. Many methods of sedation have been described but theirs side effects are the limitations. Dexmedetomidine, a selective alpha2 adrenergic agonist, has unique property of conscious sedation. Besides, dexmedetomidine has additional property of analgesia, reflex blunting and anti-sialogogue, which can further improve the success rate of awake-fibreoptic intubation in cases with difficult airway. We described a case of bear maul of face with anticipated difficult airway successfully conducted awake-fibreoptic intubation with the use of dexmedetomidine.
\end{abstract}

Keywords: airway management; dexmedetomidine; facial injury

How to cite this article: Parajuli BD, Udaya RK, Sharma A, Shrestha GS. Dexmedetomidine as an anaesthetic adjunct for management of difficult airway in a patient with facial injury following bear maul. JSAN 2015;2:77-79.

Corresponding author: Bashu Dev Parajuli, MD

Lecturer, Department of Anaesthesiology

Tribhuvan University Teaching Hospital,

Maharajgunj, Kathmandu, Nepal

Phone: +9779841844277/+97714600633

Email: bashuparajuli2012@gmail.com 


\section{Introduction}

The management of difficult airway is one of the most challenging tasks for the anaesthesiologist. Life threatening "cannot intubate and cannot ventilate" situation can be avoided by performing awake-fibreoptic intubation. ${ }^{1}$ Although there are many techniques described for fibreoptic intubation but relative merits and demerits of them should be considered. The key to successful fibreoptic intubation depends upon adequacy of preparation which includes: 1. Preoperative assessment of the patient 2. Careful explanation of the procedure to the patient 3 . Setting the stage 4. Preparation of the equipments to be used. 5. Preparing the patient (antisialagogue, sedation, nerve blocks, application of the topical anaesthetic, etc). If these preparations are meticulously carried out, the likelihood of successful and comfortable fibreoptic intubation is greatly increased. ${ }^{2}$

Many methods of sedation for fibreoptic intubation, such as benzodiazepines, propofol or opioids, have been defined but they have their own limitations. These challenging patients may be benefited from dexmedetomidine, a selective $\alpha 2$ adrenergic agonist, which have been used clinically for its sympatholytic, analgesic and sedative effects. ${ }^{3} \mathrm{~A}$ sedation regimen using low-dose dexmedetomidine combined with titrated doses of benzodiazepines and ultra-short acting narcotics with local airway anaesthesia has been used for airway manipulation.

We report a case of anticipated difficult airway (ventilation, laryngoscopy and intubation) due to bear maul of face, successfully managed with dexmedetomidine for awakefibreoptic intubation.

\section{Case report}

A 35 years old male, with no previous co-morbidities, presented with avulsion of face due to bear maul for 1 day. On local examination of face (Figure 1), there was loss of bilateral cheeks, nose and lips exposing both jaws and almost all teeth. There was inferior orbital and nasal bone fracture and exposed maxillary sinuses. Besides, there was fracture of body and ramus of mandible. The inter-incisor distance was less than $3 \mathrm{~cm}$ but neck movement and thyromental distance was normal (Figure 1).Vital parameters, systemic examination findings and preoperative investigation reports were normal.

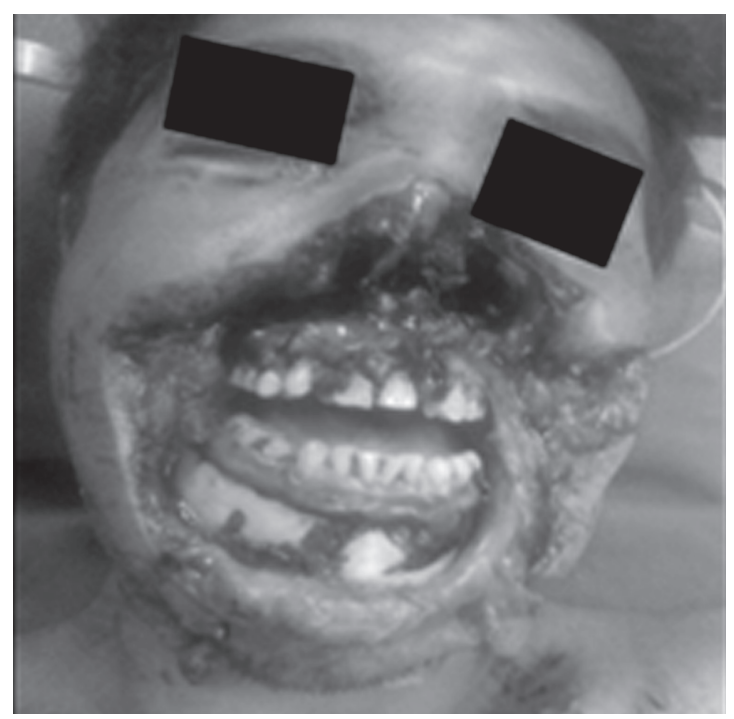

Figure 1: Avulsion of face due to bear maul.

Debridement and primary repair of face was planned. Patient was explained about steps of awake-intubation and also risk-benefit of the procedure. Intravenous (IV) cannula was secured in dorsum of right hand with 18 guage cannula. He was premedicated with Glycopyrrolate $0.2 \mathrm{mg}$ and Dexamethasone $4 \mathrm{mg}$ IV. Then, patient was nebulized with Inj $4 \%$ Lignocaine $2 \mathrm{ml}$ for 20 minutes before the procedure. It was followed by bilateral superior laryngeal nerve block with Inj $2 \%$ Lignocaine $2 \mathrm{ml}$ on each side. Transtracheal nerve block was also performed with Inj 2\% Lignocaine $3 \mathrm{ml}$.

Patient was then shifted to the operating room and $100 \%$ oxygen was insufflated using the simple facemask for 5 minutes and oxygen at $6 \mathrm{~L} / \mathrm{min}$ was supplemented via nasal catheter, introduced into the nasopharynx. Dexmedetomidine was started at a dose of $1 \mathrm{mcg} / \mathrm{kg}$ over 10 minutes and then followed in infusion at the dose of 0.2 to $0.4 \mathrm{mcg} / \mathrm{kg} /$ hour. William's airway was placed in the oral cavity during which mild cough was present, so two puffs of $10 \%$ lidocaine locally in the oropharynx and 25 mcg Fentanyl IV was administered. Fibrescope preloaded with a size $7.5 \mathrm{~mm}$ flexometallic endotracheal tube was negotiated through the airway towards the vocal cord. On first attempt, vocal cord could not be visualized due to technical problem in the bronchoscope. On second 
attempt, fiberscope could be successfully negotiated through the vocal cords and endotracheal tube was railroaded through the vocal cords. Tracheal intubation was confirmed by capnography and bilateral auscultation. During this procedure, his Richmond Agitation Sedation Score was +1 to +2 . After the confirmation of tube, Propofol $80 \mathrm{mg}$, Fentanyl 100 micrograms and Vecuronium $6 \mathrm{mg}$ IV was administered. Intermittent positive pressure ventilation was then initiated. The tube was fixed to the edge of the right cheek with silk 2.0 sutures and the throat pack was placed. Maintenance of anaesthesia was done with isoflurane in oxygen, dexmedetomidine and vecuronium. After debridement and primary repair, dexmedetomidine and inhalation agent were stopped and residual neuromuscular blockade was reversed with neostigmine and glycopyrrolate. After removing throat pack, extubation of trachea was performed when the patient was awake. Patient was then shifted to the post operative ward. His postoperative period was uneventful.

\section{Discussion}

We demonstrate the successful use of IV dexmedetomidine in combination with topical anaesthesia and low dose fentanyl bolus for awake-fibreoptic intubation in a case with anticipated difficult airway due to bear maul. Thus, the complications due to failed mask ventilation and intubation after induction and paralysis could be avoided.

During fibreoptic intubation, spontaneous ventilation with patient cooperation should be maintained throughout the procedure for which adequate topical and regional anesthesia is essential. ${ }^{1}$ Sedation cannot be a substitute for inadequate regional anaesthetic preparation of airway. ${ }^{2}$ Although some anaesthesiologist may choose to use no sedation, however, appropriate use of sedatives can render this experience less distressing for patients. Narcotic analgesics could provide mild sedation, analgesia and reduction of airway reactivity, but there is a risk of aspiration and apneic spell. The disadvantage of using benzodiazepines was their effect on consciousness, respiration and cardiovascular status. ${ }^{2}$

Dexmedetomidine provides conscious sedation avoiding side effects of narcotic and benzodoazepams. ${ }^{2,4,5}$ Besides, it provides hemodynamic and sympathoadrenal stability by reducing the circulating catecholamines. ${ }^{6}$ Chu et al reported that a loading dose $(1 \mu \mathrm{g} / \mathrm{kg})$ of intravenous dexmedetomidine over no less than 10 minutes provided conscious sedation without respiratory depression or upper airway obstruction. ${ }^{7}$ It can be used either as the sole agent or an adjuvant to facilitate awake intubation in patients with anticipated difficult airways. ${ }^{2}$ In our case, we used a loading dose of $1 \mu \mathrm{g} / \mathrm{kg}$ of dexmedetomidine over 10 minutes followed by regional block and later topped up with Fentanyl to meet the target sedation and perform awake intubation comfortably.
Glycopyrrolate premedication improves visualization during bronchoscopy. It reduces the secretions, improving the visualization. The dry mucosa is better anaesthesized by the topical local anaesthetic agents. ${ }^{8}$ Its vagolytic property counteracts bradycardia that could be caused by dexmedetomidine. Dexmedetomidine also has antisialogue property by its sympatholytic and vagomimetic effects. ${ }^{8}$ In our case, we used glycopyrollate $0.2 \mathrm{mg}$ IV 30 minutes prior to the procedure.

Dexmedetomidine appeared to provide preservation of patent airway, good intubating conditions and hemodynamic stability with less adverse effects, thus serving as a useful adjunct for awake-fibreoptic intubation in the management of difficult airway cases as supported by many studies. ${ }^{9-10}$ Comparative studies with other techniques, involving a larger population are needed to generalize the findings of this case.

\section{Conflict of interest statement}

\section{References}

1. Ovassapian A. Fibreoptic Endoscopy and the Difficult Airway. 2nd edition. New York: Lippincott- Raven; 1996:201-30.

2. Walsh ME, Shorten GD. Preparing to perform an awake-fibreoptic intubation. Yale journal of biology and medicine 1998;78:537-49.

3. Gertler R, Brown HC, Mitchell DH, Silvius EN. Dexmedetomidine: a novel sedative-analgesic agent. Proc (Bayl Univ Med Cent) 2001;14:13-21.

4. Belleville JP, Ward DS, Bloor BC. Effects of intravenous dexmedetomidine in humans. I. Sedation, ventilation and metabolic rate. Anesthesiology 1992;77:1125-33.

5. Abdelmalak B, Makary L, Hoban J, Doyle DJ. Dexmedetomidine as sole sedative for awake intubation in management of the critical airway. J Clin Anesth 2007;19:370-3.

6. Lawrence CJ, De Lange S. Effects of a single pre-operative dexmedetomidine dose on isoflurane requirements and perioperative haemodynamic stability. Anaesthesia 1997;52:736-44.

7. Chu KS, Wang FY, Hsu HT, Lu IC, Wang HM, Tsai CJ. The effectiveness of dexmedetomidine infusion for sedating oral cancer patients undergoing awake-fibreoptic nasal intubation. Eur J Anaesthesiol 2010;27:36-40.

8. Watanabe $\mathrm{H}$, Lindren L, Rosenberg P, Randell T. Glycopyrronium prolongs topical anaesthesia of the oral mucosal and enhances absorption of lignocaine. BJA 1993;70:94-5.

9. Maroof M, Khan R, Jain D. Dexmedetomidine is a useful adjunct for awake intubation. Can J Anesth 2005;52:776-7.

10. Johnston KD, Rai MR. Conscious sedation for awakefibreoptic intubation: a review of the literature. Can J Anaesth 2013;60:58499. 